\title{
SAFEGUARDING INTANGIBLE CULTURAL HERITAGE THROUGH EDUCATION AND TRAINING (EGYPTIAN PERSPECTIVE)
}

Badawi ISMAIL *

Conservation Department,.Faculty of Archaeology, Luxor University, Egypt

\begin{abstract}
The goal of this study is to analyse the approaches and categories that underpin the educational programmes related to intangible heritage in Egypt, inventoried by our team. We need to define the question and provide guidelines concerning the main issues to be borne in mind in designing programmes for such a sensitive area as intangible heritage, the ultimate aim being to contribute towards the improvement of future designs. The study shows that the educational programmes under scrutiny belong to a broad range of typologies within intangible heritage and have several shortcomings in their educational design. This is indeed a source of concern in view of the important role played by Heritage Education in raising the awareness of people and guaranteeing unifying processes to ensure that cultural expressions become part of the community's shared heritage.

Keywords

Intangible Heritage, Cultural Expression, Hand Crafts, Lifelong Learning, Educational Programs
\end{abstract}

\section{Introduction}

The scientific field that studies the relationship between intangible heritage and education is constantly evolving as a result of the proliferation of research. Over the last few decades a large number of studies have produced theoretical constructs and a frame of reference which have no doubt succeeded in bridging the initial gap. In the case of Egypt, we will refer to contributions by authors and institutions. From a more international perspective, the topic has been discussed by many scholars. Besides this ample theoretical canon, there has also been an increase in the amount of research on heritage and education, including that conducted in the formal sphere which addresses the teaching of heritage-related contents in the classroom.. The use of technological resources in the implementation of research has been the main focus of international publications by numerous authors. A more relational approach involving the connections between schools, community, lifelong learning and identity is illustrated by many works. We can even find studies which position heritage education as a key discipline in the context of cultural heritage management, by underscoring its potential for supporting processes like value-enhancement, awareness-raising or community ownership of cultural heritage. Regarding the connection between heritage education and people with disabilities or special educational needs, where educational programs are evaluated which are adapted to several target groups with the purpose of developing a model for inclusion.

\footnotetext{
*Corresponding author: badawi_16@yahoo.com
} 
All the above-mentioned studies are rooted in the need to position heritage education as a central discipline in the safeguarding and management of cultural heritage, both tangible and intangible. Heritage education is thus understood as a guarantee that has the potential to raise the awareness of the community and to activate new links between culture and society while ensuring the transformation of cultural assets into heritage assets.

This overview of international research work and benchmark projects, will lets us focus on the observation and analysis of intangible heritage education in Egypt. The subject has been addressed not only by a number of institutions, but also by numerous legislative and regulatory frameworks like Institute of Folklore (Academy of Arts) Ministry of Culture and Egyptian Society For Folk Traditions ( ESFT).

This study of research will be conducted under the auspices of TVET (UNESCOUNEVOC). The research problem will arise from early analyses may claiming that intangible heritage is not prioritised content in educational programmes, even though there are very interesting proposals in this regard which possess a technical educational value. Moreover, among proposals implemented in non-formal settings there is a large variability (and a fair amount of dispersal too), which will points to the need to order and classify them appropriately.

The situation described above, on the other hand, takes place in a country that can boast many properties included in the World Heritage List as well as elements that enjoy the status of intangible heritage inscribed on UNESCO's Representative List of the Intangible Cultural Heritage of Humanity.

All of this justifies the need to thoroughly scrutinise educational actions put into practice in Egypt over the last few years regarding intangible cultural heritage. Such is the inspiration for our research, the goal of which is to appraise and shed light on the available education opportunities in the field of intangible cultural heritage in Egypt through TVET is an emerging opportunity but not yet widely established. In order to achieve this end, the present study will collect the results of analyses conducted on approaches and categories informing educational programmes related to intangible heritage, in order to define the state of the question and provide guidelines concerning the main issues to be borne in mind in designing programmes for such a sensitive area as intangible heritage, the ultimate aim being to contribute towards the improvement of programme design in the future. As far as our line of research (intangible cultural heritage education) is concerned, to explore connections with technical education, language acquisition and development. 


\section{The Study Analytical Method:}

Besides diagnosing and formulating the state of the question, the study will define a method in order to inventory, analyse and evaluate educational programmes. Disseminating the results of this method is indeed one of the observation's goals. The study will inventory programmes and proposals in the field of intangible heritage education, both national and international. Regarding the observation's research structure - one supported by two successive and interrelated projects - research can be distinguished.

The implementation of this study will generate a large database that lists events, programmes, projects, plans, teaching materials, networks, conferences, courses, competitions, etc. that have been produced in Egypt over the last decade. Together with that database, the Website will provide a tool for the dissemination of heritage education initiatives and will create the Observatory's own work.

\section{Sequential Procedure for Program Evaluation:}

The study method will start by searching and tracing programs by using pre-established search indexes. Later on, findings are inventoried after applying a number of inclusion/exclusion criteria. The data to be used to carry out a descriptive-statistical analysis of programs so as to discern their heritage and educational typologies. It of occurrence of such actions with regard to the type of project involved.

\section{The Outcome:}

Educational programs are documents that detail and organize an educational process by systematically collecting a set of activities aimed at achieving well-defined purposes. They involve forecasting and planning ahead for continuity, and they are generally framed within the educational sphere. Our goal, therefore, was to find out the extent to which those educational programs fulfill those requirements and recommend how TVET systems and institutions can support actions towards safeguarding $\mathrm{ICH}$.

This we do by analyzing the Intangible Cultural Heritage typology used, the targeted educational stages, the teaching-learning strategies involved, the potential for adaptation and the evaluation tools.

\section{Intangible Cultural Heritage Typology to be used in the Programs:}

The concept of cultural heritage has evolved and expanded over the last century. Indeed, it has moved from a perspective where the monumental, the artistic and the ancient were the main values deserving protection to another, focused on lifestyles, social practices, knowledge, techniques and beliefs or belief systems shared by the several individuals and groups (National Plan for the Safeguarding of Intangible Cultural Heritage) as Egypt committed to adopt 2003 
ICH Convention in 2006.

Within the current decade, the use of adjectives like intangible or immaterial has become widespread in order to vindicate recognition of this dual reality and attach the importance they deserve to the so-called intangible assets. This is also reflected within the field of heritage education by the emergence over the last ten years of many different educational programs relating to intangible cultural heritage. The latter, in turn, can be divided into several typologies depending on the nature of its manifestations based on how the Safeguarding of Intangible Cultural Heritage education programs to be inserted within the curriculum of the technical education adopted by TVET .

There are five domains where ICH manifests itself according to the Convention for the Safeguarding of the Intangible Cultural Heritage:

a) oral traditions and expressions, including language as a vehicle of the intangible cultural heritage;

b) performing arts;

c) social practices, rituals and festive events;

d) knowledge and practices concerning nature and the universe;

e) traditional craftsmanship.

Depending on the ICH typology used in each educational program, the latter's goals may differ substantially. We therefore asked ourselves: which typologies of intangible cultural heritage are being used and worked on for the most part? In order to answer our question, we will carry out an analysis of intangible cultural heritage typologies that are present in our educational programs, which will indicate that the typology that is most often used is social practices, rituals and festive events. Interesting as well as valuable is the fact that all of them are represented in the programs under scrutiny.

\section{The School Environment and Educational Stage:}

Before starting the analysis of didactic designs, we think it appropriate to highlight the environment where these programs will implemented so as to better understand their real operation. Most previous programs analyzed (64.3\%) are conducted in formal settings. They can be categorized as belonging to two modalities: on the one hand those implemented on the initiative of schools and within their premises; and on the other, those (which constitute the larger part) where schools engage in a collaboration with institutions in their environment like museums, local councils and associations. Students targeted by these programs are variously distributed across the several educational stages. The educational stage the highest concentration of programs will focus on Technical Education Schools which adopt TVET 
programs, together with the category 'Various educational stages', where programs do not address a specific educational stage but a broader range of students.

\section{Typologies of Teaching-Learning and Their Representative Programs:}

When analyzing the kinds of teaching-learning strategies proposed in the programs, we have to classified the latter into four non-mutually exclusive categories: Narration, Workshop, Didactic Resource and Others, which are in turn subdivided into several subcategories. The most widely recorded strategy in working on intangible cultural heritage is the use of narratives. Within them, traditional guided tours constitute the most widespread modality, possibly because they can be adapted to audiences with different ages and needs.

\section{Program Categories Depending on Teaching-Learning Strategy:}

- Narration

- Guided Tour

- Didactic Guided Tour

- Lecture

- Workshop

- Plastic Arts

- Performing Arts

- Experiential

- Creation of Didactic Materials

- Didactic Resource

- Didactic Unit

- Pedagogical Concept

- ICTs

- Exhibition

\section{Goals and Evaluation:}

Regarding program goals, we found that many programs would require a detailed study of the curriculum and the basic skills involved in the educational stage they target in order to achieve a more balanced design. We have to detect that appreciation for the wealth and diversity of natural, social and cultural heritage, as well as the development of individual and social responsibility in the preservation of intangible cultural heritage, are most often the declared goals, followed, albeit to a lesser extent, by others concerning the availability of spaces for experience-transmission and inter-generational exchange, heritage-driven motivation for students of technical education, or issues related to values involved in living together, such as team work or the enhancement of inter-cultural awareness, where we believe 
heritage has a lot to offer.

\section{CONCLUSIONS:}

Our study will set out to analyses the approaches and categories involved in educational programs on intangible heritage to be inventoried by our team, how can TVET support actions towards safeguarding $\mathrm{ICH}$, and the specifics actions and activities to be undertaken by UNESCO-UNEVOC in order to support TVET institutions (UNEVOC Centres) to safeguarding ICH. Our research would prove that there are shortcomings in several aspects of educational designs. One of the main deficiencies that we have to spotted is the degree of adaptation of programs to the needs and interests of a range of target groups. This is a surprising flaw if we bear in mind that diversity is present in all spheres of contemporary life.

On the other hand, and despite the limitations of our study, we have to detect good examples of highly original practice and programs in the area of intangible heritage. A high proportion of these take place in the formal sphere and in collaboration with other institutions in their neighboring environment - an interesting issue insofar as this entails the participation of all educational agents.

\section{References:}

- Adamson, Glenn. The Invention of Craft. $1^{\text {st }}$ ed. London: A \& C Black Publishers, 2012.

- Auther, Elissa. String, Felt, Thread: The Hierarchy of Art and Craft in American Art. $1^{\text {st }}$ ed. Minneapolis: University of Minnesota Press, 2010.

- Bratich, Jack Z., and Heidi M. Brush. "Fabricating Activism: Craft-Work, Popular Culture, Gender." Utopian Studies 22.2 (2011): 233-260. Web. 1 Jan. 2017.

- Broecke, Lara, and Cennino Cennini. Cennino Cennini's Il Libro Dell'arte. $1^{\text {st }}$ ed. London: Archetype Publications, 2015.

- Bryant, Julius, and Susan Weber. John Lockwood Kipling: Art and Crafts in the Punjab and London. 1st ed. New Haven: Yale University Press, 2017.

- Buszek, Maria Elena. "'Labor Is My Medium": Some Pespective (S) On Contemporary Craft." Archives of American Art Journal 50.3/4 (2011): 66-75.

- Charny, Daniel. Power of Making: The Importance of Being Skilled. $1^{\text {st }}$ ed. London: Victoria \& Albert Museum, 2011.

- Coatts, Margot. Pioneers of Modern Craft. $1^{\text {st }}$ ed. Manchester: Manchester University Press, 1997.

- Cooke Jr., Edward S. "Modern Craft and the American Experience." American Art 21.1 (2007): 2-9. 
- Dormer, Peter. "The Language and Practical Philosophy of Craft." The Culture of Craft. Peter Dormer. $1^{\text {st }}$ ed. Manchester: Manchester University Press, 1997. 219-230.

- Frayling, Christopher. On Craftmanship: Towards A New Bauhaus. $1^{\text {st }}$ ed. London: Oberon Books, 2011.

- Greenhalgh, Paul. "Introduction: Craft in a Changing World." The Persistence of Craft. Paul Greenhalgh. $1^{\text {st }}$ ed. London: A\&C Black, 2002. 1-17.

- Hamilton, Laura. Radical Craft: Alternative Ways of Making. $1^{\text {st }}$ ed. Birmingham: Craftspace, 2016.

- Harrod, Tanya. The Crafts in Britain in the 20Th Century. $1^{\text {st }}$ ed. New Haven: Yale University Press, 1999.

- Pastor, Julia. "The Materiality of Tapestry in the Digital Age." The Journal of Modern Craft 9.3 (2016): 289-311.

- Portisch, Anna Odland. "The Craft of Skilful Learning: Kazakh Women's Everyday Craft Practices in Western Mongolia." Journal of the Royal Anthropological Institute 16 (2010): S62-S79.

Received: August 15, 2019

Accepted: October 20, 2019 